\title{
Effectiveness of intervention on physical activity of children: systematic review and meta-analysis of controlled trials with objectively measured outcomes (EarlyBird 54)
}

\author{
(c) $)$ (1) \& 8 OPEN ACCESS
}

\author{
Brad Metcalf research fellow and statistician ${ }^{1}$, William Henley professor of medical statistics ${ }^{2}$, \\ Terence Wilkin professor of endocrinology and metabolism ${ }^{1}$
}

${ }^{1}$ Department of Endocrinology and Metabolism, Peninsula College of Medicine and Dentistry, Plymouth University Campus, Plymouth, UK; ${ }^{2}$ Institute of Health Services Research, Peninsula College of Medicine and Dentistry, University of Exeter Campus, Exeter, UK

\begin{abstract}
Objective To determine whether, and to what extent, physical activity interventions affect the overall activity levels of children.

Design Systematic review and meta-analysis.

Data sources Electronic databases (Embase, Medline, PsycINFO, SPORTDiscus) and reference lists of included studies and of relevant review articles.

Study selection Design: randomised controlled trials or controlled clinical trials (cluster and individual) published in peer reviewed journals. Intervention: incorporated a component designed to increase the physical activity of children/adolescents and was at least four weeks in duration. Outcomes: measured whole day physical activity objectively with accelerometers either before or immediately after the end of the intervention period.

Data analysis Intervention effects (standardised mean differences) were calculated for total physical activity, time spent in moderate or vigorous physical activity, or both for each study and pooled using a weighted random effects model. Meta-regression explored the heterogeneity of intervention effects in relation to study participants, design, intervention type, and methodological quality.

Results Thirty studies (involving 14326 participants; 6153 with accelerometer measured physical activity) met the inclusion criteria and all were eligible for meta-analysis/meta-regression. The pooled intervention effect across all studies was small to negligible for total physical activity (standardised mean difference $0.12,95 \%$ confidence interval 0.04 to $0.20 ; P<0.01$ ) and small for moderate or vigorous activity $(0.16,0.08$ to $0.24 ; P<0.001)$. Meta-regression indicated that the pooled intervention effect did not differ significantly between any of the subgroups (for example, for total physical activity, standardised mean differences were 0.07 for age $<10$ years and 0.16 for $\geq 10$ years, $P=0.19$;
\end{abstract}

0.07 for body mass index across the entire range and 0.22 for exclusively overweight/obese children, $\mathrm{P}=0.07 ; 0.12$ for study duration $\leq 6$ months and 0.09 for $>6$ months, $\mathrm{P}=0.71 ; 0.15$ for home/family based intervention and 0.10 for school based intervention, $\mathrm{P}=0.53$; and 0.09 for higher quality studies and 0.14 for lower quality studies, $\mathrm{P}=0.52$ ).

Conclusions This review provides strong evidence that physical activity interventions have had only a small effect (approximately 4 minutes more walking or running per day) on children's overall activity levels. This finding may explain, in part, why such interventions have had limited success in reducing the body mass index or body fat of children.

\section{Introduction}

Physical activity is associated with many health benefits, ${ }^{1-3}$ but most children fail to meet national recommendations. ${ }^{4-6}$ Prevention of obesity in particular is thought to be one of the benefits to being more active, and accordingly most interventions aimed at reducing childhood obesity incorporate a physical activity component. Observational studies consistently show that greater activity is associated $(r \sim-0.2)$ with lower body mass index and girth, ${ }^{7-11}$ yet physical activity interventions to date have been largely unsuccessful in improving the body mass index or body composition of children, ${ }^{12-14}$ and understanding the reasons for this is important. One explanation, for which some evidence exists, ${ }^{15}$ is that more activity leads to higher calorie consumption, offsetting any gains in energy expenditure. Another, yet more fundamental, is that physical activity interventions do not increase the activity of children sufficiently for it to affect adiposity.

To date, all systematic reviews that have explored the effectiveness of physical activity interventions on the activity 
levels of children have had important limitations. For example, the reviews did not confine their analyses to whole day activity or to objectively measured outcomes, ${ }^{12}{ }^{16}$ although both may be vital to their interpretation. These reviews included a large proportion of studies that relied on questionnaires, which offer a poor surrogate for objectively measured physical activity $(r \sim 0.1-0.3) \cdot{ }^{18-20}$ More importantly, questionnaires are liable to bias through expectancy, raised awareness, or both. ${ }^{21}$

Accelerometers, by contrast, are considered the criterion method for measuring free living activity and correspond well to activity related energy expenditure. ${ }^{22}{ }^{23}$ The existing reviews also include studies that measured activity only during intervention specific periods of the day (for example, physical education classes, break/recess times, school hours only), and the effects observed during such periods may not be representative of the intervention's effect on whole day physical activity.

The primary aim of this review was to determine whether, and to what extent, physical activity interventions increase the overall activity of children, using a meta-analysis approach. The second aim was to examine the effects of the intervention in relation to potential study level covariates by using meta-regression. The review follows the PRISMA guidelines for the preferred conduct and reporting of systematic reviews and meta-analyses. ${ }^{24}$

\section{Methods}

\section{Inclusion criteria}

Studies had to meet all of the following criteria for inclusion in this review.

Population-Participants had to be aged 16 years or younger.

Intervention - The intervention must have incorporated a component that aimed to increase physical activity. The control condition must not have incorporated an activity/exercise related element of any kind. The intervention period needed to be at least four weeks.

Outcomes-Physical activity must have been measured objectively by using accelerometry in the same participants at both baseline and follow-up. We included only studies that measured "follow-up physical activity" before or immediately after the end of the intervention period (within four weeks). Whole day activity had to be reported as total physical activity volume (usually expressed as "mean accelerometer counts/minute"), time spent in moderate or vigorous intensity activity (time spent in activities of at least the intensity of brisk walking, usually expressed as "minutes/day" or "proportion of day"), or both. We excluded studies that reported only "part day" activity levels.

Study design-Studies had to be randomised controlled trials or controlled clinical trials (cluster or individual).

\section{Search strategy}

We searched four electronic databases (Embase, Medline, PsycINFO, and SPORTDiscus) for articles published in peer reviewed journals from January 1990 to early March 2012. We imposed no language restriction. We used search terms relevant to childhood (child*, youth, adolescen*, juvenile, teen*, infant*, boy*, girl*), an activity intervention (physical activity, activ*, exercis*, training, sedentary, obesity, overweight, BMI), type of trial (randomised, controlled, trial, RCT, intervention), and an objective measure of activity (objective*, acceleromet*, activity monitor, actigraph, MTI, CSA, actical, actiheart, tritrac, unidimensional, triaxial, MVPA). Two reviewers independently assessed the abstracts retrieved from this electronic search for potentially eligible studies. When the abstract clearly showed that the study was not suitable, the study was discarded. We obtained full text for studies that seemed to be potentially eligible and also for those that could not be excluded on the basis of the abstract information alone. We compared the abstracts selected for full text retrieval by each reviewer at this stage and resolved any discrepancies by discussion. The same two reviewers independently assessed the full text articles and selected studies that met the inclusion criteria, again resolving any discrepancies by discussion. We also searched the reference lists of relevant review articles and of the articles that met the inclusion criteria. Finally, we checked the articles that met the inclusion criteria for duplicate reporting of the same data.

\section{Data extraction}

One reviewer extracted information on study level covariates and the results of the trial, and a second reviewer checked it. We extracted information on study participants (percentage of girls, baseline age, body mass index, and activity level), size, duration, setting of intervention (for example, home, school, or community based), the physical activity component of the intervention, the method for measuring activity (type and model of accelerometer, requested number of days the accelerometers were to be worn, and when follow-up measure was taken: during or after the intervention), and dimensions of study quality/risk of bias (randomisation, proportion lost to follow-up, analysed with intention to treat approach) as potential effect modifiers.

We extracted result specific information for total physical activity, moderate or vigorous physical activity, or both. The type of data extracted differed according to the way in which the results were reported. Where available, we extracted relevant model statistics ( $F$ statistic, $t$ statistic, or $\mathrm{P}$ value), "group $\times$ time" model coefficients, the between group mean difference (difference in "activity change from baseline" or difference in "follow-up activity" controlled for baseline activity), or the within group means (mean change from baseline or raw means at both baseline and follow-up). For model derived statistics or coefficients, we extracted information on the covariates wherever possible. We also extracted the corresponding measures of precision (standard deviations, standard errors, or $95 \%$ confidence intervals) for all means and coefficients. Finally, we extracted the total number of participants involved in each study and the number who provided valid accelerometer data.

\section{Calculating effect sizes}

Not all studies used the same type of accelerometer. As a result, the units for both outcomes (total physical activity and moderate or vigorous physical activity) were not the same across all studies, so we standardised them. As both outcome measures were continuous variables, the intervention effects of each study were represented by the standardised mean difference in outcome, calculated for this review by dividing the between group difference in mean activity change from baseline (or follow-up activity controlled for baseline activity) by the pooled standard deviation of activity change from baseline. We used the "MAd" package for R statistical software (R.2.13.0) to calculate the effect size (its variance and $95 \%$ confidence interval) for each study by using Hedges' $g .{ }^{25}$ When a trial reported the within group means and standard deviations at baseline and follow-up separately, we assumed a correlation of $r=0.5^{426}{ }^{27}$ between baseline and follow-up activity to estimate the standard deviation for activity change from baseline. Where studies reported only one of either total physical activity or moderate or vigorous physical activity, we emailed the corresponding author requesting the other. Where moderate 
intensity activity and vigorous intensity activity were reported separately, we combined them to obtain measures of moderate or vigorous activity.

Where studies reported multiple comparisons (such as for girls and boys, for two time points, for groups receiving different interventions, or for two different cohorts), we calculated a standardised mean difference for each comparison separately. Where a study did not report the combined effect and variance, we calculated the weighted mean of the multiple effects as described by Borenstein and colleagues. ${ }^{28}$ For comparisons that were not independent of one another (for example, multiple time points in the same cohort), we adjusted the combined variance for the degree of correlation between the comparisons, again assuming it to be $r=0.5$ if not stated. ${ }^{46}{ }^{27} \mathrm{We}$ extracted and analysed only comparisons based on outcomes measured during or immediately after the intervention; measures taken more than one month after the end of the intervention period were not included in the analysis.

\section{Calculating an overall summary effect size}

We combined the effect sizes of all the included studies to estimate an overall summary effect size (and 95\% confidence interval) for both total physical activity and moderate or vigorous physical activity by using a random effects meta-analysis model weighted by the inverse of the effect variances (MAd package in R.2.13.0). An overall standardised mean difference of $\sim 0.2$ is considered small, $\sim 0.5$ is moderate, and $\sim 0.8$ is large.$^{29} \mathrm{We}$ assessed heterogeneity among the study effects by a visual inspection of the forest plots and by the $\mathrm{I}^{2}$ statistic. We used both to help to determine whether continuing with our secondary aim-examining study level covariates as possible sources of heterogeneity-was appropriate.

\section{Effect sizes relative to study level covariates}

For this analysis, the studies were not necessarily represented by a single effect size. We did not pool multiple comparisons within a study, considering them to be independent samples. The notable exception was for multiple time points, for which the two effects are clearly not independent of each other. We pooled multiple time points for all analyses except that which explored "duration" as a potential effect modifier.

We grouped all comparisons according to baseline characteristics of the study population (sex: exclusively boys and exclusively girls; age: $<10$ years and $\geq 10$ years; body mass index status: all categories and exclusively overweight/obese; activity level: total physical activity $<500$ counts/minute and $\geq 500$ counts/minute); study design (duration: $\leq 6$ months and $>6$ months; study size: $n<200$ and $n \geq 200$; methodological quality: quality score $\leq 2 / 3$ and quality score $=3 / 3$; timing of follow-up: during intervention and after intervention); and the type of intervention (setting: home/family based and school based; activity sessions provided as part of intervention: yes/no). We entered each of these dichotomous variables into a weighted random effects meta-regression model separately ("metafor" package in R.2.13.0). We then entered all variables into a multivariate meta-regression model using a backward elimination approach with a removal criterion of $\mathrm{P}>0.05$. In addition, we analysed the covariates that we extracted as continuous variables to test whether the relation was linear and consistent with the findings of the categorical analysis. We calculated the proportion of total between study variance explained by the model and reported it as $\mathrm{R}^{2}{ }^{30}$

\section{Sensitivity analysis}

We used two recommended forms of sensitivity analysis to verify the reliability of the meta-analysis results. ${ }^{31}$ Firstly, we varied the assumed correlation of $r=0.5$ between baseline and follow-up activity from $r=0.3$ to $r=0.7$ for all relevant studies to see if this altered the overall summary estimates. Secondly, we did quality specific subgroup analysis to assess whether the overall intervention effect changed when studies deemed to be of "lower" methodological quality were excluded.

\section{Publication bias}

We assessed publication bias by using two funnel plots, both regarding total physical activity. The first plotted the standardised mean differences, and the second plotted the residuals produced from the meta-regression model containing the associated study level covariates. We did the second one to test whether any asymmetrical scatter of the mean differences, indicative of publication bias, could alternatively be explained by differences in studies' characteristics.

\section{Results}

\section{Literature search}

The electronic search identified 344 potentially eligible reports (fig $1 \Downarrow$ ). We were able to exclude 286 of these on the basis of the title or abstract alone. Of the 58 articles for which we retrieved full text, a further 30 were excluded. We found two additional eligible articles from searching the reference lists of the 28 eligible articles and of relevant review articles, bringing the total number of studies to $30 .{ }^{32-61}$

\section{Studies' characteristics}

All eligible articles had been published between May 2003 and December 2011. The studies varied in size, duration, and intervention type (see web extra table). Study sizes ranged from 18 to 2840 participants (median 307, total 14326 ), and the number of children providing accelerometer based measures of physical activity in each study ranged from 18 to 1138 (median 165 , total 6153). The duration of follow-up ranged from 4 weeks to 140 weeks (median 26 weeks); nine studies reported an intervention effect at two time points (mid-intervention and end of intervention). Seventeen of the trials were school based, 10 were home/family based, one was community centre based, one was university gym based, and one was boy scout centre based. Nineteen studies provided activity/exercise sessions as part of the intervention, and 11 did not.

\section{Participants' characteristics}

Of the 6153 children with appropriately measured activity, 3232 were girls and 2921 were boys. Two studies included girls only, ${ }^{43} 54$ two included boys only, ${ }^{42} 55$ and 26 included both girls and boys (the proportion of girls ranged from $27 \%$ to $64 \%$, median $51 \%$ ), although only four of these reported sex specific results. ${ }^{37} 39456$ The mean age at baseline varied from 1.8 to 13.1 years (median 9.8 years). Eight studies involved exclusively overweight/obese participants $(n=691)$, and the rest involved children recruited from all body mass index categories.

\section{Types of outcome measures}

Of the 30 eligible studies, 21 reported total physical activity, 23 reported moderate or vigorous physical activity, and 14 reported both. Where an article reported only one of these outcomes, we emailed the corresponding author for the other. 
Six authors responded, increasing the number of studies for which we could analyse total physical activity to $25(n=4386)$ and moderate or vigorous physical activity to $25(\mathrm{n}=5001)$. Twenty-six studies used uni-axial accelerometers to measure activity (23 with the CSA/MTI Actigraph, two with the IM Systems BioTrainer, and one with the Mini-Mitter Actical uni-directional model), one study used a bi-axial accelerometer (BodyMedia SenseWear Pro2 Armband), and three studies used tri-axial accelerometers (two with the Hemokinetics TriTrac-R3D and one with the Mini-Mitter Actical omni-directional model). The accelerometer data collection period varied according to study from one to 21 days. Sixteen studies stipulated at least six days, which is the minimum required to achieve at least $80 \%$ reliability in the measure of physical activity. ${ }^{62}$

\section{Methodological design and quality}

We deemed 16 studies ( $n=3883$ ) to be of "high" methodological quality, as they scored positively on all three of the quality criteria described above. Of the other 14 studies $(n=2270), 12$ scored positively on two of the quality criteria and two scored positively on just one. Losses to follow-up ranged from $0 \%$ to $46 \%$ (median 11\%); 20 studies reported less than $20 \%$ attrition. All but three of the studies carried out intention to treat analysis. Twenty-seven studies were randomised controlled trials; the remaining three were controlled clinical trials. For two of the controlled clinical trials, the intervention schools and control schools were matched appropriately on age, ethnicity, and socioeconomic status. The other trial selected schools from areas that were "broadly comparable" on several socio-demographic variables but did adjust for age, sex, and baseline activity in the analyses. Fifteen of the included studies were cluster designs, and all but two of these accounted for clustering in their analyses. For these two studies, we multiplied the reported variances by a "design factor" $(1+((\mathrm{m}-1) \times \mathrm{ICC})$, where $\mathrm{m}$ is the average number of participants in each cluster and ICC is the intra-cluster correlation), ${ }^{63}$ which decreased their respective weightings (towards the pooled effect) from $2.9 \%$ to $1.1 \%$ and from $0.9 \%$ to $0.5 \%$.

\section{Overall summary estimate}

The pooled analysis across all studies showed a statistically significant effect in favour of the intervention group for both total physical activity (standardised mean difference $0.12,95 \%$ confidence interval 0.04 to $0.20 ; \mathrm{P}<0.01)$ and moderate or vigorous physical activity $(0.16,0.08$ to $0.24 ; \mathrm{P}<0.001)$, although both seemed to be of limited clinical significance according to Cohen's definitions..$^{29}$ Hence, strong evidence exists from this analysis to suggest that physical activity interventions have a small to negligible effect on overall total physical activity and a small effect on moderate or vigorous physical activity. Figure $2 \Downarrow$ shows a forest plot of the effect sizes, confidence intervals, and percentage weighting for both activity outcomes for the individual studies and for all studies pooled. The largest weighting of any individual study for total physical activity was $11.2 \%$, and for moderate or vigorous physical activity it was $17.3 \%$. A visual inspection of the forest plots suggests that a degree of between study variation exists in terms of the effect sizes. $\mathrm{I}^{2}$ values of $38 \%$ for total activity and $51 \%$ for moderate or vigorous activity confirmed moderate levels of heterogeneity. ${ }^{64}$

\section{Effect sizes relative to study level covariates}

We used 31 intervention effects (standardised mean differences) for total physical activity and 33 for moderate or vigorous physical activity in the analyses of all but three of the study level covariates. The three exceptions were for duration ( 38 for total physical activity and 42 for moderate or vigorous activity), sex (9 and 13), and baseline activity (20 and 18). For all but two of the covariates, the degree of heterogeneity did not differ considerably between the subgroups. For study size and duration, the $\mathrm{I}^{2}$ values were very different between the subgroups (for example, for total physical activity, $\mathrm{I}^{2}=0 \%$ for larger studies and $58 \%$ for smaller studies, and $\mathrm{I}^{2}=0 \%$ for longer term studies and $50 \%$ for shorter term studies). In general, the subgroup specific $\mathrm{I}^{2}$ values were slightly lower for total physical activity than for moderate or vigorous physical activity (median $\mathrm{I}^{2}=22 \%$ and $33 \%$ with interquartile ranges of $0-40 \%$ and $12-48 \%$ ). Figure $3 \Downarrow$ shows the pooled intervention effects (with $95 \%$ confidence intervals) for the subgroups of each of the 10 study level covariates analysed. None of the differences reached statistical significance, although one was borderline. For total physical activity, the standardised mean difference was 0.15 greater for studies of overweight/obese only populations than for studies with populations recruited from all body mass index categories $(\mathrm{P}=0.07)$. Multivariate meta-regression confirmed that even when considered simultaneously, none of the study level covariates reached statistical significance (all $\mathrm{P}>0.05$ ).

Figure $4 \Downarrow$ shows the strength of linear association between the intervention effects on total physical activity and each of the continuous study level covariates (mean age, mean body mass index, study size, and study duration). Body mass index z score explained $7 \%$ of the variation in effect sizes $(\mathrm{P}=0.04)$ for which, on average, the standardised mean difference was 0.074 greater for each 1.0 increase in $\mathrm{z}$ score in mean body mass index. However, this association did not exist across the range of mean $\mathrm{z}$ scores - when we repeated the analysis without studies of overweight/obese only participants (mean $\mathrm{z}$ score $\geq 2.4$ ), the association disappeared completely $\left(\beta=0.008, P=0.69, \mathrm{R}^{2}=0.00\right)$. This observation confirms the appropriateness of analysing body mass index status as a categorical variable. None of the other continuous covariates was significantly associated with the size of the intervention effects (all $\mathrm{P}>0.18$ ).

\section{Sensitivity analysis}

The findings of this meta-analysis were robust to the assumptions that we made about the correlation between baseline and follow-up activity. When the correlation was assumed to be lower, at $r=0.3$, the resulting summary effects were standardised mean differences of 0.11 for total physical activity and 0.15 for moderate or vigorous physical activity. When the correlation was assumed to be higher, at $r=0.70$, the summary effects were standardised mean differences of 0.12 for total physical activity and 0.17 for moderate or vigorous physical activity. The meta-analysis results were also robust to the inclusion of studies of lower methodological quality, as the summary effects differed little when we excluded such studies (based only on studies with a quality score of $3 / 3$, standardised mean differences were 0.09 for total physical activity and 0.11 for moderate or vigorous physical activity; based only on randomised controlled trials, standardised mean differences were 0.11 for total physical activity and 0.13 for moderate or vigorous physical activity; based only on studies with $<20 \%$ loss to follow-up, standardised mean differences were 0.11 for total physical activity and 0.15 for moderate or vigorous physical activity; based only on studies that carried out intention to treat analysis, standardised mean differences were 0.11 for total 
physical activity and 0.13 for moderate or vigorous physical activity).

\section{Publication bias}

The funnel plots of the standardised mean differences and of the residuals (produced from the meta-regression model containing body mass index status) both showed a slightly asymmetric scatter consistent with publication bias (fig $5 \Downarrow$ ). However, we cannot rule out the possibility of the "small study effect," ${ }^{65}$ as the asymmetry was attributable to the absence of just two or three small studies producing negative effects. Whichever is the case, the absence of some small negative studies is likely to have had little effect on our findings, given that the removal of small studies producing large positive effects reduced the summary effect only from a standardised mean difference of 0.12 to 0.09 for total physical activity and from 0.16 to 0.13 for moderate or vigorous physical activity.

\section{Discussion}

This systematic review found that physical activity interventions, on average, achieved small to negligible increases in children's total activity volume, with small improvements in the time spent in moderate or vigorous intensity activities ( $\sim 4$ minutes more walking or running per day), the clinical effect of which is likely to be minimal (for example, $\sim 2 \mathrm{~mm}$ in waist circumference or $\sim 0.06 \mathrm{~mm} \mathrm{Hg}$ in systolic blood pressure). ${ }^{11}$ This review also shows that the pooled intervention effect did not differ significantly according to subgroups of study level

characteristics. Although trials of exclusively overweight/obese participants tended to be slightly more effective at increasing total activity than did those that recruited children from all body mass index categories, the pooled intervention effect for this group of studies was still small.

\section{Possible explanations}

Understanding why past attempts to increase children's activity have largely proved unsuccessful might help to improve future attempts. Where interventions have failed to increase activity or reduce body fat, authors have speculated about poor delivery or poor uptake of the activity sessions, ${ }^{46}$ or suggested that the physical activity component of the intervention was not sufficiently intense. ${ }^{34}$ However, although these reasons are intuitive and plausible, they are difficult to test. An alternative explanation could be that the intervention specific exercise sessions may simply be replacing periods of equally intense activity. For example, after school activity clubs may simply replace a period of time that children usually spend playing outdoors or replace a time later in the day/week when the child would usually be active.

\section{Strengths and limitations}

This review, uniquely we believe, focuses exclusively on objectively measured, whole day physical activity.

Accelerometers are considered the criterion method for measuring free living physical activity, ${ }^{22}$ and the avoidance of studies using self reported measures meant avoidance of the bias associated with them. ${ }^{21}$ Taber and colleagues showed that for a given level of accelerometry derived activity, self reported levels of activity were significantly higher in the intervention group than in the control group. ${ }^{21}$ Although accelerometers are accepted as being limited in their ability to measure water based activities and cycling, such limitations are unlikely to have biased the results given that none of the interventions was specific to promoting swimming or cycling.
Our review also excludes studies that reported only activity differences during intervention specific parts of the day, as effect sizes derived from such short periods risk an over-estimation of whole day effects. This can be demonstrated with the results of the KISS study, in which the school time intervention effect was more than four times greater than the whole day intervention effect (total physical activity z scores $0.92 v 0.21$ ). ${ }^{32}$ The reviews by van Sluijs et al and Salmon et al incorporated studies that reported any component of activity or inactivity, including those that reported only "sedentary time" as their outcome. ${ }^{16}{ }^{17}$ Our review was specific to total physical activity and time spent in moderate or vigorous activity, as these are strongly correlated with activity related energy expenditure. ${ }^{22}{ }^{23} \mathrm{We}$ did not analyse sedentary time, as this seems to be a poor surrogate measure of total activity. ${ }^{66}$

Inevitably, some studies failed on just one of the inclusion criteria but otherwise might have made a useful contribution to the aim of this review. We excluded the TAAG trial because the baseline and follow-up measures were not paired but were collected from essentially independent samples.$^{67}$ Nevertheless, its largest intervention effect ( +1.6 minutes/day of moderate or vigorous physical activity, standardised mean difference $\sim 0.06$ ) was comparable to the findings of our review. ${ }^{67}$ Three studies that had accelerometer data at follow-up were excluded because baseline activity was measured by questionnaire only. ${ }^{68-70}$ All three produced effects sizes that were similar to the pooled estimates obtained from this meta-analysis (the STOPP study: standardised mean difference $0.11^{68}$; the LEAP and LEAP2 studies (both exclusive to overweight/obese children): standardised mean difference $\sim 0.2^{69} 70$ ). We note these data to show that the findings of our review would not have differed had they been incorporated.

Many of the potential effect modifiers that we chose to explore were evidence generated. For example, sex, age, and body mass index have all been shown to be associated with objectively measured physical activity. ${ }^{10}$ Duration, study size, and mid-intervention outcomes were also positively associated with greater reductions in sedentary time according to a previous meta-analysis. ${ }^{12}$ The reporting of information on the dose, frequency, and content of activity/exercise sessions varied so much between trials that we were obliged to dichotomise it simply as "provision of designated activity/exercise sessions: yes/no" for the purpose of analysis, being aware nevertheless that resolution of the measure might be compromised in the process. We acknowledge that within study subgroup effects would have provided a more powerful method of examining subgroup differences (that is, testing whether the intervention effect differed according to categories of risk-for example, by baseline activity or body mass index status). However, of the studies we inspected for this review, none reported such "intervention $\times$ risk" analyses.

\section{Comparisons with other recent reviews}

The findings of this review are consistent with those of a previous meta-analysis by Kamath and colleagues. ${ }^{12}$ That review was primarily concerned with the effect of behavioural interventions on the prevention of childhood obesity. It also explored the effect of physical activity interventions on activity levels, reporting an overall effect identical to the summary effect calculated in our meta-analysis (standardised mean difference 0.12 ), despite only three studies being common to both. The studies included in the review by Kamath et al were not specific to whole day activity, nor to accelerometry, and half the studies relied on questionnaire based physical activity. The authors excluded studies in overweight/obese only populations, ${ }^{12}$ and, 
when such studies are removed from our meta-analysis, the overall summary effect for total activity falls to a standardised mean difference of 0.07 . Two other systematic reviews summarising the effectiveness of interventions on physical activity were published in 2007 and reported similar findings to one another. ${ }^{16}{ }^{17}$ Salmon et al reviewed 76 studies and van Sluijs et al reviewed 57, of which $40-50 \%$ were deemed to have had a positive and statistically significant effect on activity. Both reviews reported a higher proportion of positive intervention effects in studies that measured activity objectively, compared with those that measured it by questionnaire. However, both considered "direct observation" to be an objective measure, and this may have inflated the number of positive results, given that direct observation is used only to measure short, intervention specific periods of the day (such as physical education classes or break/recess times).

\section{Context, implications for health policy, and future research}

In the mind of the public, physical inactivity is a major cause of childhood obesity, and the need to increase activity is intuitive. However, the small increase in physical activity that emerges from formal interventions seems insufficient to improve the body mass/fat of children. Understanding why physical activity interventions fail to increase activity sufficiently is important, particularly as activity is associated with better metabolic health independently of fatness. ${ }^{11}$ Accelerometers relate minute by minute data to clock time, so future studies could capture both whole day activity and the activity related to intervention specific periods. Such an approach could not only measure the real time activity response to an intervention but could also establish whether the response was subsequently subject to a degree of replacement or compensation. ${ }^{72}$ Also, future physical activity intervention studies might usefully do within study risk group analyses to examine whether the intervention does indeed achieve the intended response in those children who stand to benefit the most.

Systematic reviews and meta-analysis are not without their critics, but they nevertheless represent the best available evidence to government strategists. However counterintuitive or discomforting it may be, strong evidence from this review shows that physical activity interventions have little effect on the overall activity of children. Organised physical activity may nevertheless still offer benefits such as improved coordination skills, greater self confidence, team participation, and social inclusivity.

\section{Conclusions}

Physical activity interventions have little effect on the overall activity levels of children, which may explain, at least in part, why such interventions have had a limited effect on body mass index or body fat. The outcome of this meta-analysis questions the contribution of physical activity to the prevention of childhood obesity.

Contributors: BM was involved in the design, research, analyses, and writing of this article. WH was involved in the analysis. TW was involved in the design, research, and writing. TW is the guarantor.

Funding: EarlyBird (BM and TW) is currently supported by the Bright Future Trust, the Kirby Laing Foundation, the Peninsula Foundation, and the EarlyBird Diabetes Trust. These funding sources had no role in the study design, data collection, analysis, interpretation of results, or the writing of the report. WH was supported by the National Institute for Health Research (NIHR) Collaborations for Leadership in Applied
Health Research and Care (CLAHRC). The views expressed in this publication are those of the authors and not necessarily those of the NHS, the NIHR, or the Department of Health.

Competing interests: All authors have completed the Unified Competing Interest form at www.icmje.org/coi_disclosure.pdf (available on request from the corresponding author) and declare: no support from any organisation for the submitted work; no financial relationships with any organisations that might have an interest in the submitted work in the previous three years; no other relationships or activities that could appear to have influenced the submitted work.

Ethical approval: Not needed.

Data sharing: No additional data available.

1 Janssen I, Leblanc AG. Systematic review of the health benefits of physical activity and fitness in school-aged children and youth. Int J Behav Nutr Phys Act 2010;7:40.

2 Guinhouya BC, Samouda H, Zitouni D, Vilhelm C, Hubert H. Evidence of the influence of physical activity on the metabolic syndrome and/or on insulin resistance in pediatric populations: a systematic review. Int J Pediatr Obes 2011;6:361-88

3 Saavedra JM, Escalante Y, Garcia-Hermoso A. Improvement of aerobic fitness in obese children: a meta-analysis. Int J Pediatr Obes 2011;6:169-77.

4 Metcalf BS, Voss LD, Hosking J, Jeffery AN, Wilkin TJ. Physical activity at the government-recommended level and obesity-related health outcomes: a longitudinal study (Early Bird 37). Arch Dis Child 2008;93:772-7.

5 Riddoch CJ, Mattocks C, Deere K, Saunders J, Kirkby J, Tilling K, et al. Objective measurement of levels and patterns of physical activity. Arch Dis Child 2007;92:963-9.

6 Centers for Disease Control and Prevention (CDC). Physical activity levels of high school students_United States, 2010. MMWR Morb Mortal Wkly Rep 2011;60:773-7.

7 Ekelund U, Sardinha LB, Anderssen SA, Harro M, Franks PW, Brage S, et al. Associations between objectively assessed physical activity and indicators of body fatness in 9- to 10-y-old European children: a population-based study from 4 distinct regions in Europe (the European Youth Heart Study). Am J Clin Nutr 2004;80:584-90.

8 Andersen LB, Harro M, Sardinha LB, Froberg K, Ekelund U, Brage S, et al. Physical activity and clustered cardiovascular risk in children: a cross-sectional study (the European Youth Heart Study). Lancet 2006;368:299-304.

9 Ness AR, Leary SD, Mattocks C, Blair SN, Reilly JJ, Wells J, et al. Objectively measured physical activity and fat mass in a large cohort of children. PLoS Med 2007;4:e97.

10 Metcalf BS, Hosking J, Jeffery AN, Voss LD, Henley W, Wilkin TJ. Fatness leads to inactivity, but inactivity does not lead to fatness: a longitudinal study in children (EarlyBird 45). Arch Dis Child 2011;96:942-7.

11 Ekelund U, Luan J, Sherar LB, Esliger DW, Griew P, Cooper A. Moderate to vigorous physical activity and sedentary time and cardiometabolic risk factors in children and adolescents. JAMA 2012;307:704-12.

12 Kamath CC, Vickers KS, Ehrlich A, McGovern L, Johnson J, Singhal V, et al. Behavioral interventions to prevent childhood obesity: a systematic review and metaanalyses of randomized trials. J Clin Endocrinol Metab 2008;93:4606-15.

13 Harris KC, Kuramoto LK, Schulzer M, Retallack JE. Effect of school-based physical activity interventions on body mass index in children: a meta-analysis. CMAJ 2009;180:719-26.

14 Waters E, de Silva-Sanigorski A, Hall BJ, Brown T, Campbell KJ, Gao Y, et al. Interventions for preventing obesity in children. Cochrane Database Syst Rev 2011;12:CD001871.

15 Westerterp KR. Physical activity, food intake, and body weight regulation: insights from doubly labeled water studies. Nutr Rev 2010;68:148-54.

16 Van Sluijs EM, McMinn AM, Griffin SJ. Effectiveness of interventions to promote physical activity in children and adolescents: systematic review of controlled trials. BMJ 2007;335:703.

17 Salmon J, Booth ML, Phongsavan P, Murphy N, Timperio A. Promoting physical activity participation among children and adolescents. Epidemiol Rev 2007;29:144-59.

18 Sallis JF, Strikmiller PK, Harsha DW, Feldman HA, Ehlinger S, Stone EJ, et al. Validation of interviewer-and self-administered physical activity checklists for fifth grade students. Med Sci Sports Exerc 1996;28:840-51

19 Treuth MS, Hou N, Young DR, Maynard LM. Validity and reliability of the Fels physical activity questionnaire for children. Med Sci Sports Exerc 2005;37:488-95.

20 Basterfield L, Adamson AJ, Parkinson KN, Maute U, Li PX, Reilly JJ. Surveillance of physical activity in the UK is flawed: validation of the Health Survey for England physical activity questionnaire. Arch Dis Child 2008;93:1054-8.

21 Taber DR, Stevens J, Murray DM, Elder JP, Webber LS, Jobe JB, et al. The effect of a physical activity intervention on bias in self-reported activity. Ann Epidemiol 2009;19:316-22.

22 Puyau MR, Adolph AL, Vohra FA, Butte NF. Validation and calibration of physical activity monitors in children. Obes Res 2002;10:150-7.

23 Schmitz KH, Treuth M, Hannan P, McMurray R, Ring KB, Catellier D, et al. Predicting energy expenditure from accelerometry counts in adolescent girls. Med Sci Sports Exerc 2005;37:155-61.

24 Moher D, Liberati A, Tetzlaff J, Altman DG. Preferred reporting items for systematic reviews and meta-analyses: the PRISMA statement. BMJ 2009;339:b2535.

25 Borenstein M, Hedges LV, Higgins JP, Rothstein HR. Effect sizes based on means. In: Introduction to meta-analysis. 1st ed. John Wiley and Sons, 2009:21-32.

26 Mattocks C, Leary S, Ness A, Deere K, Saunders J, Kirkby J, et al. Intraindividual variation of objectively measured physical activity in children. Med Sci Sports Exerc 2007;39:622-9.

27 Kristensen PL, Moller NC, Korsholm L, Wedderkopp N, Andersen LB, Froberg K. Tracking of objectively measured physical activity from childhood to adolescence: the European youth heart study. Scand J Med Sci Sports 2008;18:171-8.

28 Borenstein M, Hedges LV, Higgins JP, Rothstein HR. Multiple outcomes or time-points within a study. In: Introduction to meta-analysis. 1st ed. John Wiley and Sons, 2009:225-38.

29 Cohen J. Statistical power analysis for the behavioral sciences. Lawrence Erlbaum Associates, 1987.

30 Borenstein M, Hedges LV, Higgins JP, Rothstein HR. Meta-regression. In: Introduction to meta-analysis. 1st ed. John Wiley and Sons, 2009:187-203. 


\section{What is already known on this topic}

Few children meet the recommendations for physical activity, and this is of concern as greater activity is associated with better health outcomes and less obesity

Physical activity interventions nevertheless have little effect on the prevention of childhood obesity, and the reason for this has been unclear

\section{What this study adds}

Physical activity interventions have little effect on the overall activity of children, which may explain, at least in part, why such strategies have had limited success in preventing childhood obesity

31 Borenstein M, Hedges LV, Higgins JP, Rothstein HR. Reporting the results of a meta-analysis. In: Introduction to meta-analysis. 1st ed. John Wiley and Sons, 2009:365-70.

32 Kriemler S, Zahner L, Schindler C, Meyer U, Hartmann T, Hebestreit H, et al. Effect of school based physical activity programme (KISS) on fitness and adiposity in primary schoolchildren: cluster randomised controlled trial. BMJ 2010;340:c785

33 Baranowski T, Baranowski J, Thompson D, Buday R, Jago R, Griffith MJ, et al. Video game play, child diet, and physical activity behavior change a randomized clinical trial. Am J Prev Med 2011;40:33-8.

34 Caballero B, Clay T, Davis SM, Ethelbah B, Rock BH, Lohman T, et al. Pathways: a school-based, randomized controlled trial for the prevention of obesity in American Indian schoolchildren. Am J Clin Nutr 2003;78:1030-8.

35 Cliff DP, Okely AD, Morgan PJ, Steele JR, Jones RA, Colyvas K, et al. Movement skills and physical activity in obese children: randomized controlled trial. Med Sci Sports Exerc 2011:43:90-100.

36 Goldfield GS, Mallory R, Parker T, Cunningham T, Legg C, Lumb A, et al. Effects of open-loop feedback on physical activity and television viewing in overweight and obese children: a randomized, controlled trial. Pediatrics 2006;118:e157-66.

37 Goran MI, Reynolds K. Interactive multimedia for promoting physical activity (IMPACT) in children. Obes Res 2005;13:762-71.

38 Gorely T, Nevill ME, Morris JG, Stensel DJ, Nevill A. Effect of a school-based intervention to promote healthy lifestyles in 7-11 year old children. Int J Behav Nutr Phys Act 2009;6:5

39 Haerens L, Deforche B, Maes L, Cardon G, Stevens V, De Bourdeaudhuij I. Evaluation of a 2-year physical activity and healthy eating intervention in middle school children. Health Educ Res 2006;21:911-21.

40 Harvey-Berino J, Rourke J. Obesity prevention in preschool native-american children: a pilot study using home visiting. Obes Res 2003;11:606-11.

41 Hughes AR, Stewart L, Chapple J, McColl JH, Donaldson MD, Kelnar CJ, et al. Randomized, controlled trial of a best-practice individualized behavioral program for treatment of childhood overweight: Scottish Childhood Overweight Treatment Trial (SCOTT). Pediatrics 2008;121:e539-46.

42 Jago R, Baranowski T, Baranowski JC, Thompson D, Cullen KW, Watson K, et al. Fit for Life Boy Scout badge: outcome evaluation of a troop and internet intervention. Prev Med 2006;42:181-7.

43 Klesges RC, Obarzanek E, Kumanyika S, Murray DM, Klesges LM, Relyea GE, et al. The Memphis Girls' health Enrichment Multi-site Studies (GEMS): an evaluation of the efficacy of a 2-year obesity prevention program in African American girls. Arch Pediatr Adolesc Med 2010;164:1007-14.

44 Maddison R, Foley L, Ni MC, Jiang Y, Jull A, Prapavessis H, et al. Effects of active video games on body composition: a randomized controlled trial. Am J Clin Nutr 2011:94:156-63.

45 Patrick K, Calfas KJ, Norman GJ, Zabinski MF, Sallis JF, Rupp J, et al. Randomized controlled trial of a primary care and home-based intervention for physical activity and nutrition behaviors: PACE+ for adolescents. Arch Pediatr Adolesc Med 2006;160:128-36.

46 Reilly JJ, Kelly L, Montgomery C, Williamson A, Fisher A, McColl JH, et al. Physical activity to prevent obesity in young children: cluster randomised controlled trial. $B M J$ 2006;333:1041.

47 Roemmich JN, Gurgol CM, Epstein LH. Open-loop feedback increases physical activity of youth. Med Sci Sports Exerc 2004;36:668-73.

48 Salmon J, Ball K, Hume C, Booth M, Crawford D. Outcomes of a group-randomized trial to prevent excess weight gain, reduce screen behaviours and promote physical activity in 10-year-old children: switch-play. Int J Obes (Lond) 2008;32:601-12.

49 Taylor RW, McAuley KA, Barbezat W, Strong A, Williams SM, Mann JI. APPLE Project: $2-y$ findings of a community-based obesity prevention program in primary school age children. Am J Clin Nutr 2007:86:735-42.

50 Verstraete SJ, Cardon GM, De Clercq DL, De Bourdeaudhuij IM. A comprehensive physical activity promotion programme at elementary school: the effects on physical activity, physical fitness and psychosocial correlates of physical activity. Public Health Nutr 2007;10:477-84.

51 Wafa SW, Talib RA, Hamzaid NH, McColl JH, Rajikan R, Ng LO, et al. Randomized controlled trial of a good practice approach to treatment of childhood obesity in Malaysia: Malaysian Childhood Obesity Treatment Trial (MASCOT). Int J Pediatr Obes 2011;6:e62-9.

52 Weintraub DL, Tirumalai EC, Haydel KF, Fujimoto M, Fulton JE, Robinson TN. Team sports for overweight children: the Stanford Sports to Prevent Obesity Randomized Trial (SPORT). Arch Pediatr Adolesc Med 2008;162:232-7.

53 Wilson DK, Evans AE, Williams J, Mixon G, Sirard JR, Pate R. A preliminary test of a student-centered intervention on increasing physical activity in underserved adolescents. Ann Behav Med 2005;30:119-24.
54 Robinson TN, Matheson DM, Kraemer HC, Wilson DM, Obarzanek E, Thompson NS, et al. A randomized controlled trial of culturally tailored dance and reducing screen time to prevent weight gain in low-income African American girls: Stanford GEMS. Arch Pediatr Adolesc Med 2010;164:995-1004.

55 Peralta LR, Jones RA, Okely AD. Promoting healthy lifestyles among adolescent boys: the Fitness Improvement and Lifestyle Awareness Program RCT. Prev Med 2009;48:537-42.

56 Farpour-Lambert NJ, Aggoun Y, Marchand LM, Martin XE, Herrmann FR, Beghetti M. Physical activity reduces systemic blood pressure and improves early markers of atherosclerosis in pre-pubertal obese children. J Am Coll Cardiol 2009;54:2396-406.

57 Fitzgibbon ML, Stolley MR, Schiffer LA, Braunschweig CL, Gomez SL, Van HL, et al. Hip-Hop to Health Jr. Obesity Prevention Effectiveness Trial: postintervention results. Obesity (Silver Spring) 2011;19:994-1003.

58 Wilson DK, Van Horn ML, Kitzman-Ulrich H, Saunders R, Pate R, Lawman HG, et al. Results of the "Active by Choice Today" (ACT) randomized trial for increasing physical activity in low-income and minority adolescents. Health Psychol 2011;30:463-71.

59 Bäcklund C, Sundelin G, Larsson C. Effects of a 2-year lifestyle intervention on physical activity in overweight and obese children. Adv Physiother 2011;13:97-109.

60 Puder JJ, Marques-Vidal P, Schindler C, Zahner L, Niederer I, Burgi F, et al. Effect of multidimensional lifestyle intervention on fitness and adiposity in predominantly migran preschool children (Ballabeina): cluster randomised controlled trial. BMJ 2011;343:d6195

61 Magnusson KT, Sigurgeirsson I, Sveinsson T, Johannsson E. Assessment of a two-yea school-based physical activity intervention among 7-9-year-old children. Int J Behav Nutr Phys Act 2011;8:138.

62 Basterfield L, Adamson AJ, Pearce MS, Reilly JJ. Stability of habitual physical activity and sedentary behavior monitoring by accelerometry in 6- to 8-year-olds. J Phys Act Health 2011:8:543-7.

63 Cochrane Collaboration. Cochrane handbook for systematic reviews of interventions. 2011. www.cochrane-handbook.org.

64 Higgins JP, Thompson SG, Deeks JJ, Altman DG. Measuring inconsistency in meta-analyses. BMJ 2003;327:557-60.

65 Borenstein M, Hedges LV, Higgins JP, Rothstein HR. Publication bias. In: Introduction to meta-analysis. 1st ed. John Wiley and Sons, 2009: 277-91

66 Marshall SJ, Biddle SJ, Gorely T, Cameron N, Murdey I. Relationships between media use, body fatness and physical activity in children and youth: a meta-analysis. Int $J$ Obes Relat Metab Disord 2004;28:1238-46.

67 Webber LS, Catellier DJ, Lytle LA, Murray DM, Pratt CA, Young DR, et al. Promoting physical activity in middle school girls: Trial of Activity for Adolescent Girls. Am J Prev Med 2008;34:173-84.

68 Marcus C, Nyberg G, Nordenfelt A, Karpmyr M, Kowalski J, Ekelund U. A 4-year, cluster-randomized, controlled childhood obesity prevention study: STOPP. Int J Obes (Lond) 2009;33:408-17.

69 McCallum Z, Wake M, Gerner B, Baur LA, Gibbons K, Gold L, et al. Outcome data from the LEAP (Live, Eat and Play) trial: a randomized controlled trial of a primary care intervention for childhood overweight/mild obesity. Int J Obes (Lond) 2007:31:630-6.

70 Wake M, Baur LA, Gerner B, Gibbons K, Gold L, Gunn J, et al. Outcomes and costs of primary care surveillance and intervention for overweight or obese children: the LEAP 2 randomised controlled trial. BMJ 2009;339:b3308.

71 Riddoch CJ, Bo AL, Wedderkopp N, Harro M, Klasson-Heggebo L, Sardinha LB, et al. Physical activity levels and patterns of 9- and 15-yr-old European children. Med Sci Sports Exerc 2004;36:86-92.

72 Frémeaux AE, Mallam KM, Metcalf BS, Hosking J, Voss LD, Wilkin TJ. The impact of school-time activity on total physical activity: the activitystat hypothesis (EarlyBird 46). Int J Obes (Lond) 2011:35:1277-83.

\section{Accepted: 21 August 2012}

\section{Cite this as: BMJ 2012;345:e5888}

This is an open-access article distributed under the terms of the Creative Commons Attribution Non-commercial License, which permits use, distribution, and reproduction in any medium, provided the original work is properly cited, the use is non commercial and is otherwise in compliance with the license. See: $\mathrm{http}: / /$ creativecommons.org/licenses/by$\mathrm{nc} / 2.0 /$ and http://creativecommons.org/licenses/by-nc/2.0/legalcode. 


\section{Figures}

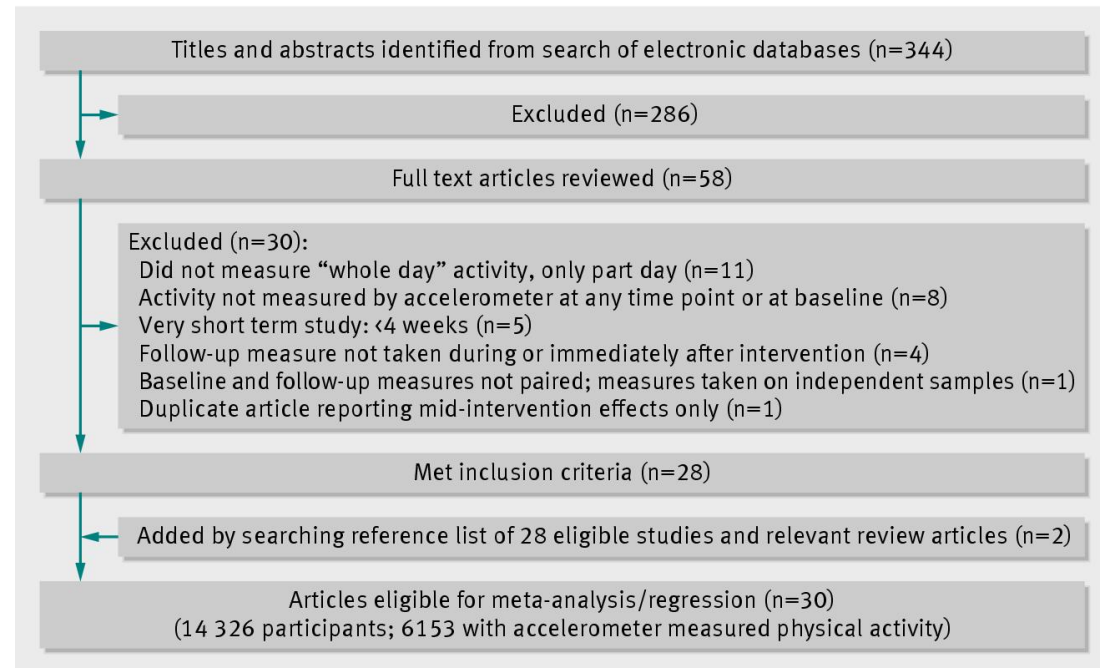

Fig 1 Summary of study selection process 


\section{Study}

Harvey-Berino 2003

Caballero 2003

Roemmich 2004

Goran 2005

Wilson 2005

Patrick 2006

Jago 2006

Goldfield 2006

Reilly 2006

Haerens 2006

Verstraete 2007

Taylor 2007

Hughes 2008

Weintraub 2008

Salmon 2008

Gorely 2009

Peralta 2009

Farpour-Lambert 2009

Kriemler 2010

Cliff 2011

Robinson 2010

Klesges 2010

Baranowski 2011

Maddison 2011

Wafa 2011

Fitzgibbon 2011

Wilson 2011

Bäcklund 2011

Puder 2011

Magnusson 2011

Summary effect
Total physical activity

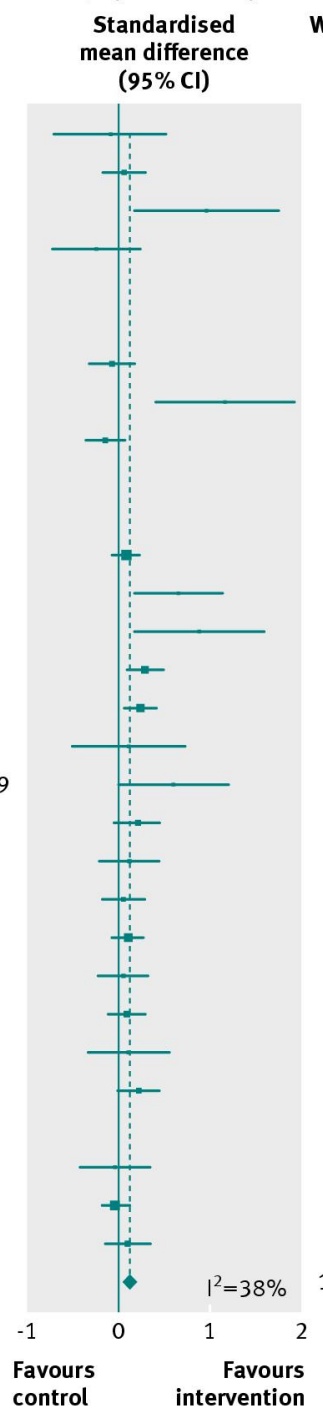

\section{Weight Standardised \\ mean difference \\ ( $95 \% \mathrm{Cl})$}

$0.7 \quad-0.09$ (-0.70 to 0.52$)$

$4.6 \quad 0.06$ (-0.17 to 0.29)

$0.4 \quad 0.96$ (0.17 to 1.75 )

$1.1-0.24(-0.75$ to 0.27$)$

NA NA

NA NA

$4.3-0.07$ (-0.31 to 0.17$)$

$0.5 \quad 1.16$ (0.40 to 1.92$)$

$5.9-0.14$ (-0.35 to 0.07$)$

NA NA

NA NA

$10.8 \quad 0.09$ (-0.06 to 0.24$)$

$1.1 \quad 0.65$ (0.17 to 1.13 )

$0.5 \quad 0.88$ (0.17 to 1.59 )

$6.5 \quad 0.29$ (0.09 to 0.49 )

8.10 .24 (0.07 to 0.41)

$0.7 \quad 0.11$ (-0.50 to 0.72$)$

$0.7 \quad 0.60$ (0.01 to 1.19)

$5.9 \quad 0.21$ (-0.03 to 0.45$)$

$2.3 \quad 0.12$ ( -0.21 to 0.45$)$

$4.6 \quad 0.05$ (-0.18 to 0.28$)$

$8.1 \quad 0.10$ (-0.07 to 0.27$)$

$3.4 \quad 0.05$ (-0.22 to 0.32)

$6.5 \quad 0.09$ (-0.11 to 0.29)

$1.3 \quad 0.11$ (-0.33 to 0.55)

$4.6 \quad 0.22(-0.01$ to 0.45$)$

NA

$1.8-0.04(-0.42$ to 0.34$)$

$11.2-0.04$ (-0.18 to 0.10$)$

$4.3 \quad 0.10(-0.14$ to 0.34$)$

$100.0 \quad 0.12$ (0.04 to 0.20 )
Moderate or vigorous physical activity

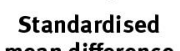

Standardised mean difference ( $95 \% \mathrm{Cl})$

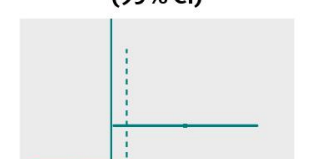

Standardised

mean difference

$(95 \% \mathrm{Cl})$

NA NA

NA NA

$0.5 \quad 0.80$ (0.03 to 1.57$)$

$1.1-0.34$ (-0.86 to 0.18$)$

$0.5 \quad 1.11$ (0.36 to 1.86$)$

$7.7 \quad 0.03$ ( -0.15 to 0.21$)$

$4.2-0.09$ (-0.33 to 0.15$)$

$0.5 \quad 0.90$ (0.17 to 1.63$)$

$5.6-0.20(-0.41$ to 0.01$)$

3.30 .31 (0.04 to 0.58 )

2.10 .54 (0.20 to 0.88 )

NA NA

$1.10 .40(-0.08$ to 0.88$)$

$0.5 \quad 0.79$ (0.05 to 1.53)

$5.6 \quad 0.24$ (0.03 to 0.45$)$

$7.7 \quad 0.26$ (0.09 to 0.44$)$

$0.7 \quad 0.03$ (-0.59 to 0.65$)$

NA NA

$5.8 \quad 0.44$ (0.17 to 0.71$)$

$2.3 \quad 0.16(-0.17$ to 0.49$)$

$4.5 \quad 0.06$ (-0.17 to 0.29$)$

$\begin{array}{ll}7.7 & 0.09 \\ (-0.09 \text { to } 0.27)\end{array}$

$3.3 \quad 0.11(-0.16$ to 0.38$)$

6.20 .02 (-0.18 to 0.22$)$

$1.3 \quad 0.36(-0.08$ to 0.80$)$

$4.5 \quad 0.27$ (0.04 to 0.50$)$

$17.30 .13(0.02$ to 0.24$)$

$1.7 \quad 0.00(-0.38$ to 0.38$)$

NA NA

$4.2 \quad 0.05(-0.19$ to 0.29$)$

$100.0 \quad 0.16(0.08$ to 0.24$)$

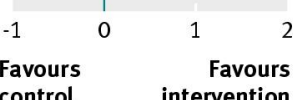

Fig 2 Forest plot showing standardised mean difference in change in physical activity between intervention and control groups for each included study. NA=not available 


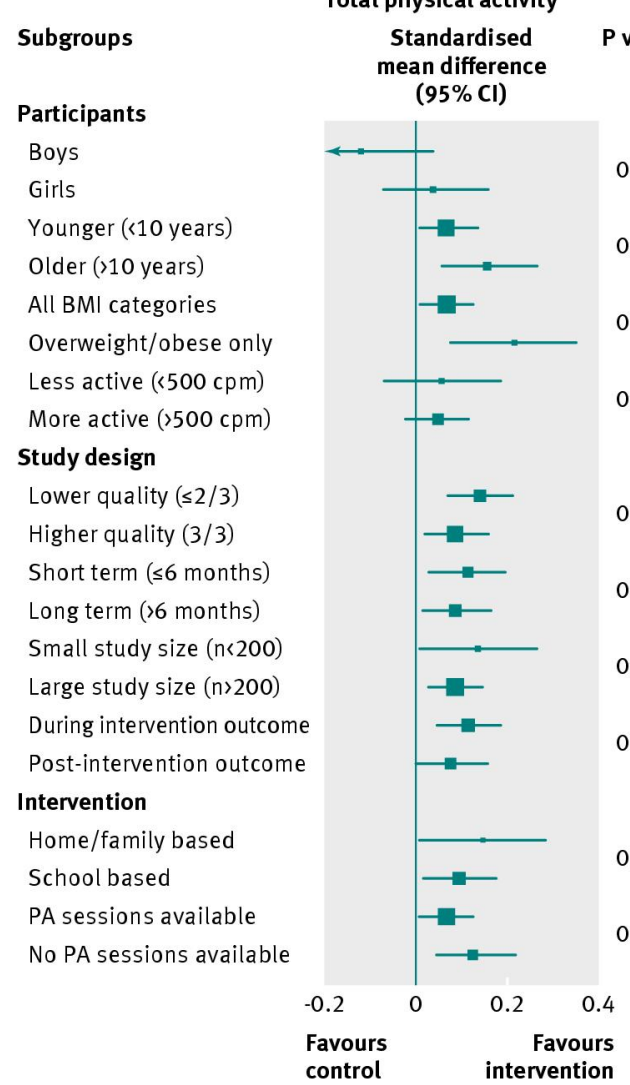

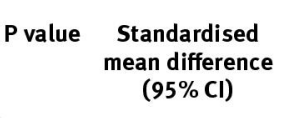

$0.10-0.12(-0.27$ to 0.04$)$ $0.04(-0.07$ to 0.16$)$

0.190 .07 (0.01 to 0.14$)$ 0.16 (0.06 to 0.26$)$ 0.07 (0.01 to 0.13$)$ $0.07 \quad 0.22$ (0.08 to 0.36 ) $0.06(-0.07$ to 0.19$)$ 0.880 .05 (-0.02 to 0.12$)$

0.520 .14 (0.07 to 0.21) 0.09 (0.03 to 0.16 )

0.710 .12 (0.03 to 0.20$)$ 0.09 (0.02 to 0.17$)$

$0.50 \quad 0.14$ (0.01 to 0.27) 0.09 (0.03 to 0.15)

0.560 .12 (0.05 to 0.19$)$ 0.08 (0.00 to 0.16 )

0.15 (0.01 to 0.28$)$ 0.10 (0.02 to 0.17$)$ 0.07 (0.01 to 0.13) 0.13 (0.05 to 0.22)

\section{Moderate or vigorous physical activity}

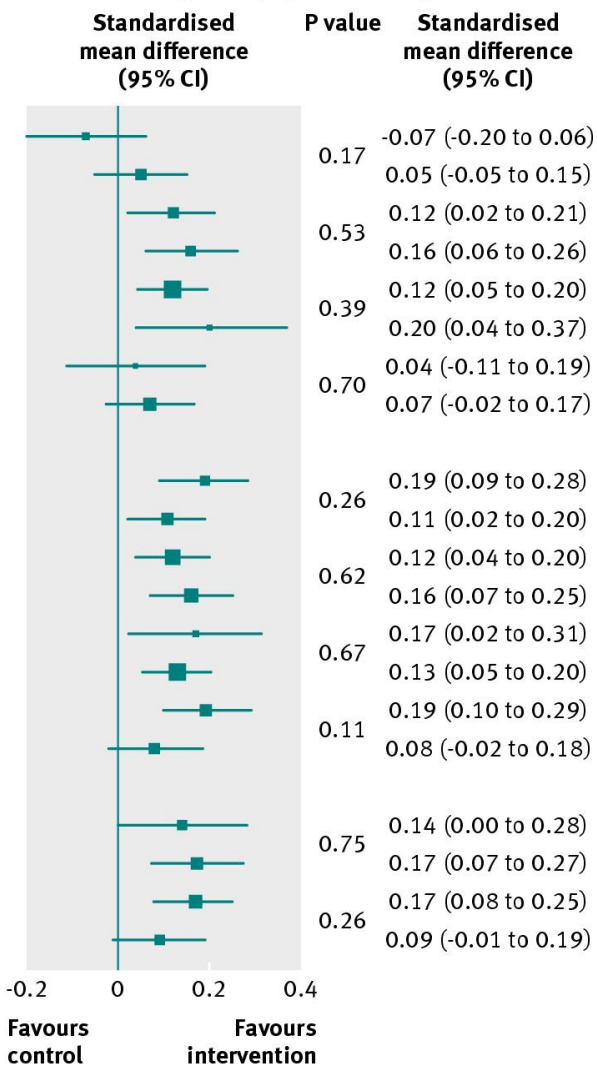

Fig 3 Standardised mean differences in changes in physical activity between intervention and control groups by subgroups of studies. $\mathrm{BMI}=$ body mass index; $\mathrm{cpm}=$ counts per minute; $\mathrm{PA}=$ physical activity

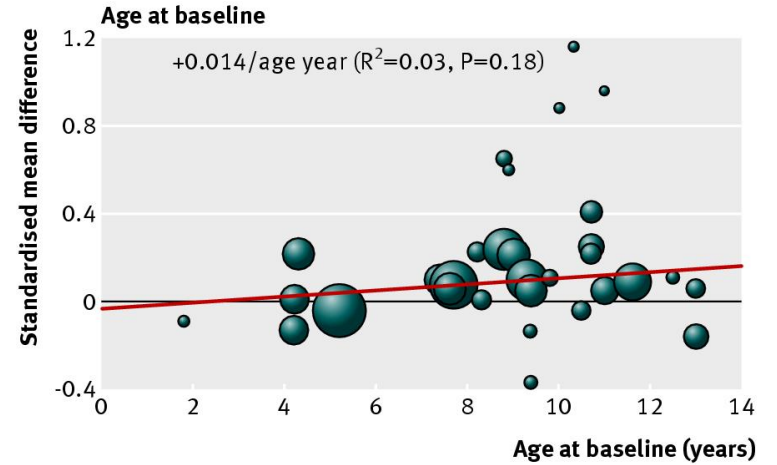

Study size

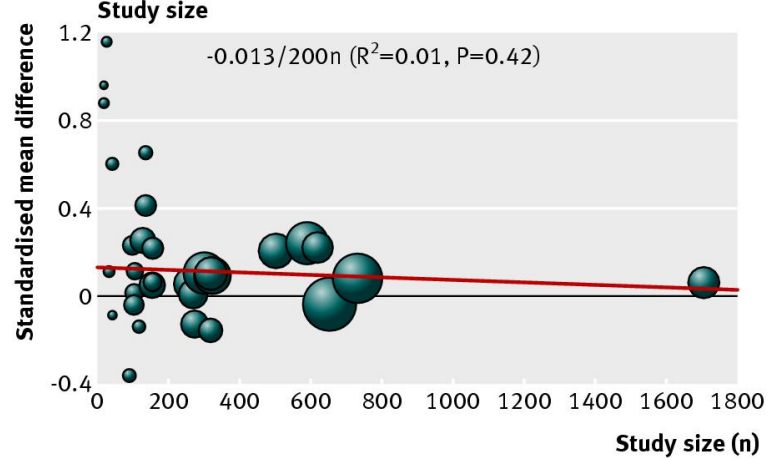

BMI at baseline

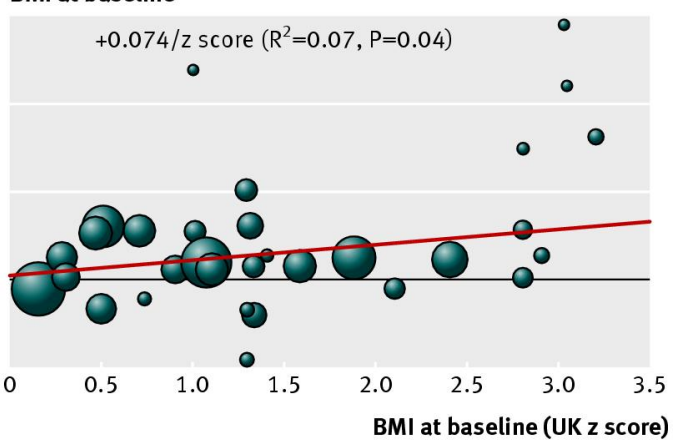

Study duration

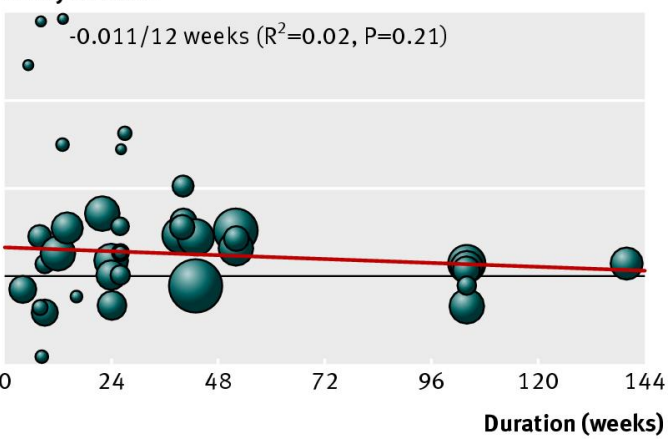

Fig 4 Intervention effects in total physical activity in relation to continuous study level covariates: age at baseline (top left), body mass index (BMI) at baseline (top right), study size (bottom left), and study duration (bottom right) 

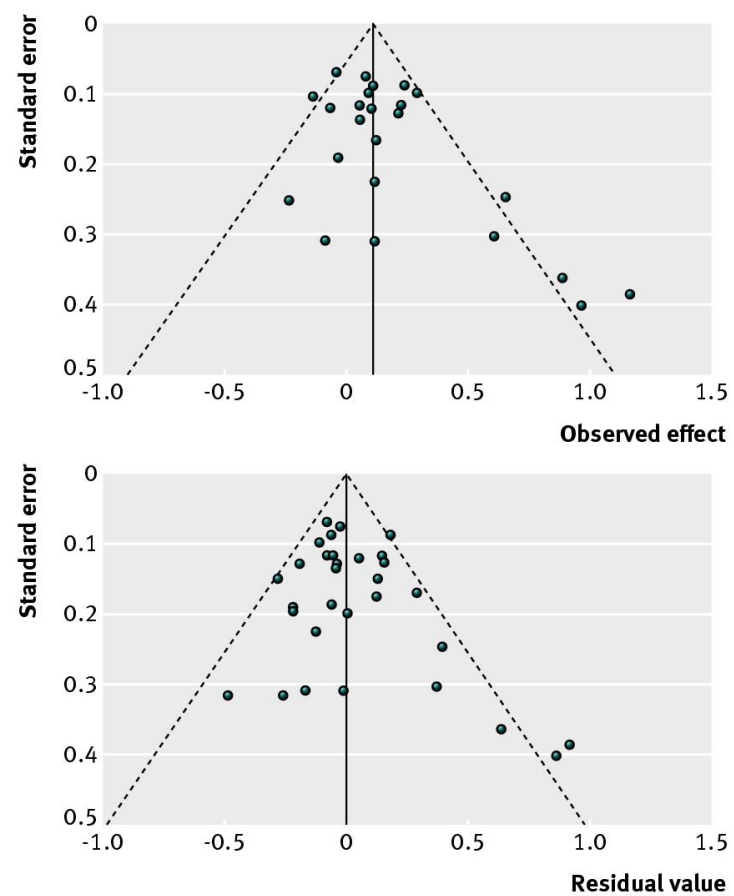

Fig 5 Assessment of publication bias: funnel plots of observed effects in total physical activity for each study (top) and meta-regression residuals of total physical activity for each comparison with body mass index status as a study level covariate (bottom) 